\title{
The death domain-containing protein Unc5CL is a novel MyD88-independent activator of the pro-inflammatory IRAK signaling cascade
}

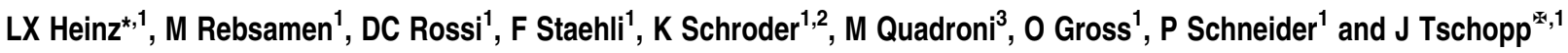

The family of death domain (DD)-containing proteins are involved in many cellular processes, including apoptosis, inflammation and development. One of these molecules, the adapter protein MyD88, is a key factor in innate and adaptive immunity that integrates signals from the Toll-like receptor/interleukin (IL)-1 receptor (TLR/L-1R) superfamily by providing an activation platform for IL-1R-associated kinases (IRAKs). Here we show that the DD-containing protein Unc5CL (also known as ZUD) is involved in a novel MyD88-independent mode of IRAK signaling that culminates in the activation of the transcription factor nuclear factor kappa B (NF- $\kappa$ B) and c-Jun N-terminal kinase. Unc5CL required IRAK1, IRAK4 and TNF receptor-associated factor 6 but not MyD88 for its ability to activate these pathways. Interestingly, the protein is constitutively autoproteolytically processed, and is anchored by its $\mathrm{N}$-terminus specifically to the apical face of mucosal epithelial cells. Transcriptional profiling identified mainly chemokines, including IL-8, CXCL1 and CCL20 as Unc5CL target genes. Its prominent expression in mucosal tissues, as well as its ability to induce a pro-inflammatory program in cells, suggests that Unc5CL is a factor in epithelial inflammation and immunity as well as a candidate gene involved in mucosal diseases such as inflammatory bowel disease. Cell Death and Differentiation (2012) 19, 722-731; doi:10.1038/cdd.2011.147; published online 9 December 2011

The TLR/IL-1R superfamily of receptors has a fundamental role in shaping the immune response by integrating signals from pathogen-associated molecular patterns and the highly inflammatory cytokines $\mathrm{IL}-1$ and $\mathrm{IL}-18^{1,2}$ All of these receptors, with the prominent exception of TLR3, utilize the Toll-IL-1R (TIR) and death domain (DD)-containing adapter protein MyD88 to induce a signal transduction pathway that culminates in the activation of the pro-inflammatory transcription factor NF- $k \mathrm{~B}$ and mitogen-activated protein kinases. ${ }^{3-7}$ Upon ligand-induced receptor dimerization, MyD88 is recruited to the cytosolic TIR domain via homotypic TIR-TIR interactions. This can either happen directly or via the adapter protein TIRAP/Mal. MyD88 then nucleates the assembly of a ternary protein complex via DD-dependent recruitment and activation of the kinases IRAK1, IRAK2 and IRAK4..$^{8,9}$ Together with the E3-ubiquitin ligase TRAF6 these factors mediate further propagation of the signal. ${ }^{10}$

The importance of the TLR/L-1R signaling axis in health and disease is highlighted by the association with a multitude of human malignancies. These include not only the susceptibility of MyD88- and IRAK4-deficient patients to pyogenic bacterial infections, but also its implication in inflammatory disorders, autoimmunity and cancer. ${ }^{11-13}$

DD-containing proteins, including MyD88 and IRAKs, are also involved in many cellular signaling processes, including apoptosis, inflammation and development. ${ }^{14,15} \mathrm{~A}$ functionally heterogeneous subgroup of these proteins is characterized by the presence of a tripartite domain module, termed the ZU5-UPA-DD supramodule, which in addition to a DD, contain a ZU5 (domain present in ZO-1 and Unc5) and a UPA (domain conserved in Unc5, PIDD and Ankyrin) domain. ${ }^{16}$ In mammals, this family comprises PIDD (p53-induced protein with a DD), Ankyrins1-3, the transmembrane receptors Unc5A-D and the poorly characterized protein Unc5CL (Figure 1a). Based on the resolution of the crystal structure of the intracellular part of Unc5B, Wang et al. ${ }^{16}$ proposed a conserved activation mechanism for these molecules, in which the ZU5 domain sequesters both the UPA and DD, keeping them in an auto-repressed state.

Unc5CL was proposed in a single study as a negative regulator of $\mathrm{NF}-\kappa \mathrm{B}$ in response to a variety of stimuli, including overexpression of TNF-R1, TRAF2, TRAF6, IKK $\beta$ and p65 or

\footnotetext{
${ }^{1}$ Department of Biochemistry, University of Lausanne, CH-1066 Epalinges, Switzerland; ${ }^{2}$ Institute for Molecular Bioscience, University of Queensland, St Lucia 4072 , Australia and ${ }^{3}$ Protein Analysis Facility, University of Lausanne, $\mathrm{CH}-1066$ Epalinges, Switzerland

${ }^{*}$ Corresponding author: L Heinz, Department of Biochemistry, University of Lausanne, Ch. des Boveresses 155, CH-1066, Epalinges, Switzerland.

Tel: + 4121692 5743; Fax: + 4121692 5705; E-mail: leonhard.heinz@gmail.com

"Deceased.

Keywords: NF-kappaB; JNK; death domain; mucosal immunity; chemokines

Abbreviations: DD, death domain; EDA, ectodysplasin-A ; EDAR, ectodysplasin-A receptor; IBD, inflammatory bowel disease; $I_{\kappa} \mathrm{B}$, inhibitor of kappa $\mathrm{B}$; IKK $\beta$, I $\kappa \mathrm{B}$ kinase beta; IL-1R, interleukin (IL)-1 receptor; IRAK, IL-1R-associated kinase; JNK, c-Jun N-terminal kinase; MyD88, myeloid differentiation primary response gene 88; NF- $\kappa$ B, nuclear factor kappa B; Nup98, nuclear pore complex protein 98; PIDD, p53-induced protein with a DD; PLA2G4C, phospholipase A2 group IVC; TIR, Toll-IL-1R domain; TLR, Toll-like receptor; TM, transmembrane; TNF $\alpha$, tumor necrosis factor alpha; TNFAIP3, TNF alpha-induced protein 3; TNF-RI, tumor necrosis factor receptor type I; TNFRSF9, TNF receptor superfamily member 9; TRAF6, TNF receptor-associated factor 6; Unc5CL, Unc5C-like protein; UPA, domain found in Unc5, PIDD and Ankyrins; ZU5, domain found in ZO-1 and Unc5

Received 26.4.11; revised 26.9.11; accepted 27.9.11; Edited by G Melino; published online 09.12.11
} 
a
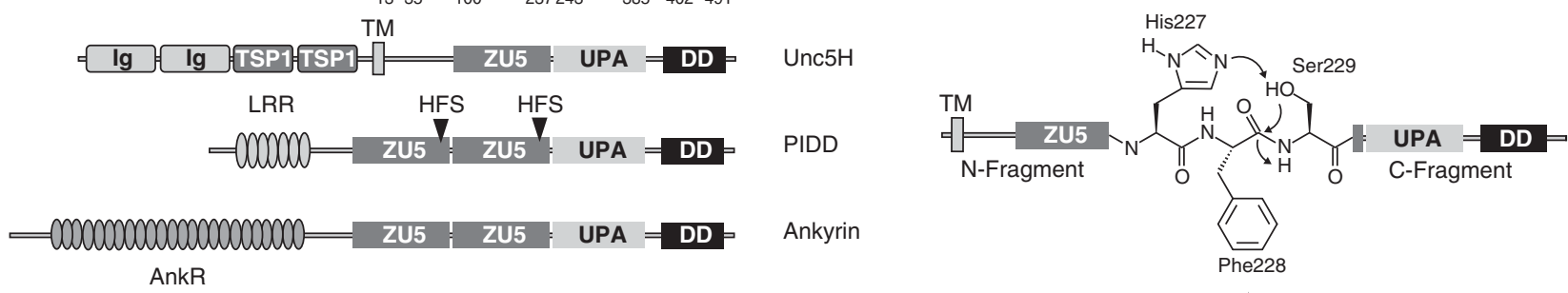

b

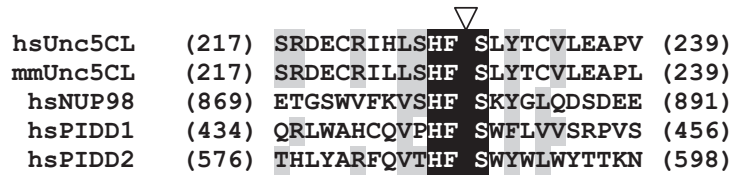

C
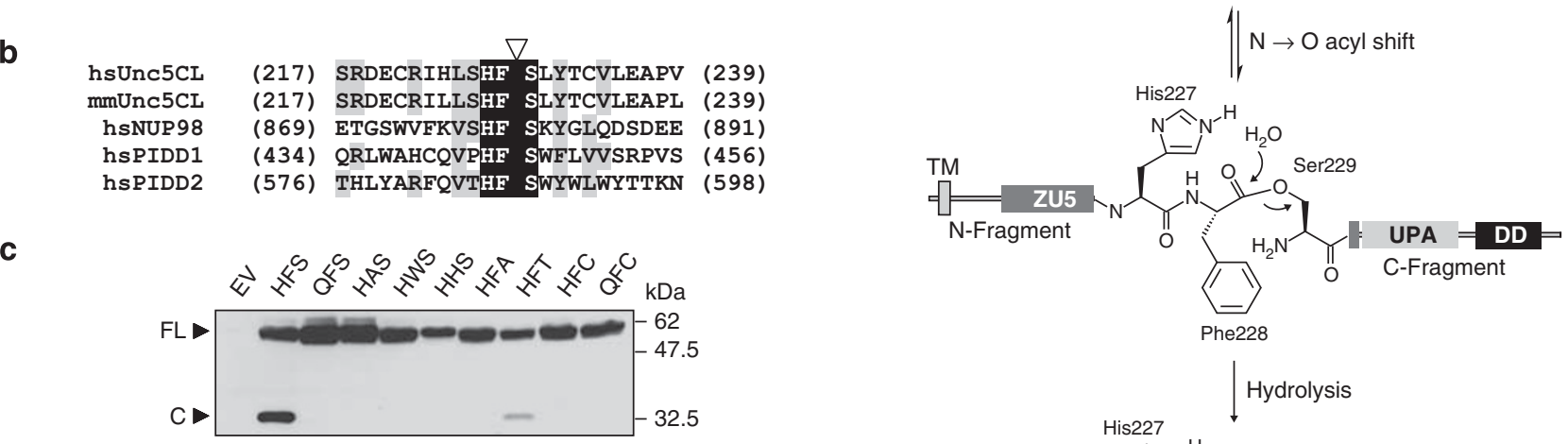

e

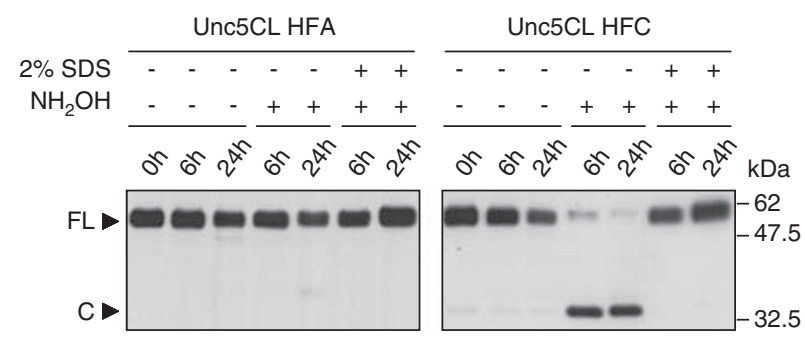

Figure 1 Domain organization and autoproteolytic processing of Unc5CL. (a) Domain organization of ZU5-UPA-DD-containing proteins. (b) Multiple sequence alignment of the protein sequences of human (hs) and murine $(\mathrm{mm})$ Unc5CL surrounding the putative autoproteolytic HFS site with the corresponding sequences from Nup98 and PIDD. Triangle: specific site of cleavage; black shading: identical amino acids; gray shading: similar amino acids. (c) HEK293T cells were transfected with the indicated C-terminally FLAG-tagged Unc5CL point mutants. FLAG-tagged proteins were analyzed by western blot. (d) Autoproteolytic cleavage mechanism at HFS sites. For autoproteolysis at the HFS site a three-step mechanism was proposed. First the histidine (His227) is involved in deprotonation of the hydroxyl group of the serine residue (Ser229). The serine hydroxyl group then functions as a nucleophile on the preceding amide bond, leading to an $\mathrm{N} \rightarrow \mathrm{O}$ acyl shift. The generated ester is then hydrolyzed, leading to cleavage between the phenylalanine and the serine residues. (e) HEK293T cells were transfected with the indicated C-terminally FLAG-tagged Unc5CL variants. FLAG-tagged proteins were immunoprecipitated, eluted and incubated or not with $200 \mathrm{mM}$ hydroxylamine $\left(\mathrm{NH}_{2} \mathrm{OH}\right) \pm 2 \% \mathrm{SDS}$ as described for the indicated time points. Proteins were analyzed by western blot. (c and e) FL, Unc5CL full-length protein; C, Unc5CL C-terminal cleavage fragment

stimulation with TNF $\alpha$ and IL-1 $\beta .{ }^{17}$ In sharp contrast to these previous observations, herein we identify Unc5CL as an inducer of a pro-inflammatory signaling cascade involving activation of NF- $\kappa \mathrm{B}$ and JNK. Dissection of the pathway reveals a striking similarity to signaling events triggered downstream of TLR/IL-1R involving the kinases IRAK1, IRAK4 and the E3-ubiquitin ligase TRAF6, but surprisingly not the adapter protein MyD88 that is usually required for IRAK/TRAF6-dependent signaling. The protein shows a highly specific tissue distribution, predominantly detectable in samples of the uterus and small intestine. Furthermore, via an N-terminal transmembrane anchor, Unc5CL is associated specifically with the apical membrane of mucosal epithelial cells. Taken together, our results uncover evidence for a hitherto-unidentified pro-inflammatory signaling pathway in mucosal epithelial cells that provides a MyD88-independent second axis of IRAK-dependent signaling in parallel to the evolutionarily conserved TLR/IL-1R system. Its pro-inflammatory activity, as well as its strikingly specific tissue distribution in mucosal epithelia implicates Unc5CL as a novel candidate molecule in mucosal inflammation, immunity and disease.

\section{Results}

Domain organization of Unc5CL. Unc5CL was first described as a novel ZU5 and DD-containing protein mostly homologous to the intracellular fragments of the Unc5-receptor family members. ${ }^{17}$ Interestingly, the resolution of the X-ray crystal structure of the rat Unc5B intracellular domain revealed a tripartite domain organization comprising the previously described ZU5 and DD, as well as a novel central UPA domain. ${ }^{16}$ To evaluate whether Unc5CL also contains such a ZU5-UPA-DD supramodule we used Jpred3 to predict the secondary structure of Unc5CL and 
compared it with experimentally determined features of rat Unc5b intracellular domains (Supplementary Figure S1). ${ }^{18}$ Pairwise alignment using ClustalW revealed $34 \%$ sequence similarity. ${ }^{19}$ In addition, most of the secondary structures were conserved among the analyzed sequences. These observations provide evidence that Unc5CL indeed contains a ZU5-UPA-DD supramodule and we annotate the ZU5 from aa 100 to 237 , the UPA from aa 243 to 385 and the DD from aa 402 to 491 (Figure 1a).

Further analysis using the transmembrane helix prediction tool TMHMM identified a previously unreported N-terminal transmembrane domain spanning aa 13-35 suggesting that Unc5CL is not a cytosolic, but membrane anchored protein (Figure 1a). ${ }^{20}$

We initially cloned the human Unc5CL cDNA from CaCo-2 cells (GenBank accession: JF681947) that corresponds to the current NCBI reference sequence (NM_173561.2). Interestingly, we observed that this sequence is different by one nucleotide from a cDNA used in a previous study on Unc5CL (GenBank: AY510109), corresponding to a nonsynonymous SNP variant (dbSNP ID: rs742493). ${ }^{17}$ This previously used variant contains a glycine at position $432(432 \mathrm{G})$ instead of a canonical arginine (432R) localized in the predicted second alpha helix of the DD (Figure 1a, Supplementary Figure S1). We therefore decided to include both Unc5CL 432G and 432R variants in our experiments.

PIDD is a ZU5-UPA-DD supramodule-containing protein that requires autoproteolytic processing at two core HFS tripeptide sites for its biogenesis and activation (Figure 1a). ${ }^{21}$ Cleavage at an HFS site is also involved in the biogenesis of the nuclear envelope protein Nup98. ${ }^{22}$ Surprisingly, by sequence comparison, we identified a bona fide HFS site in Unc5CL (aa 227-229) but not in any other ZU5-UPA-DDcontaining proteins, suggesting that Unc5CL might also undergo such autoproteolytic cleavage (Figures $1 \mathrm{a}$ and $\mathrm{b}$ and Supplementary Figure S1).

Autoproteolytic processing of Unc5CL. When Unc5CL was expressed in HEK293T cells and analyzed by western blot we could detect a band corresponding to the full-length protein at approximately $58 \mathrm{kDa}$ and a lower migrating band at approximately $32 \mathrm{kDa}$. These molecular weights correspond to the predicted size of the fragments that would be generated by cleavage of Unc5CL at the HFS site (Figure 1c). Indeed, expression of HFS point mutants impaired the appearance of the cleavage fragment of Unc5CL. Only a mutant carrying an HFT site still showed residual processing, which is consistent with the proposed requirements for this cleavage event (Figure 1d). To further corroborate the presence of an autoproteolytic HFS site in Unc5CL, we used a mutant where the serine of the HFS site is exchanged by a cysteine (HFC). Previous studies on Nup98 and PIDD have shown that this site can be cleaved involving formation of a thioester intermediate via an $\mathrm{N} \rightarrow \mathrm{S}$ acyl shift. ${ }^{21,22}$ However, cleavage of the thioester intermediate requires addition of the nucleophilic agent hydroxylamine. To test whether Unc5CL HFC also forms a thioester intermediate, we analyzed the sensitivity to hydroxylamine-induced cleavage (Figure 1e). As expected, incubation of Unc5CL HFC with hydroxylamine induced the generation of the
C-terminal cleavage fragment, which could be inhibited by pre-incubation with $2 \%$ SDS leading to protein denaturation. Taken together, these results provide evidence that, similar to Nup98 and PIDD, Unc5CL is autoproteolytically cleaved at an HFS site.

Membrane association and topology of Unc5CL. To corroborate that Unc5CL is a membrane integral protein, a TX-114 phase separation technique was applied. ${ }^{23}$ As expected, stably overexpressed Unc5CL variants with intact $\mathrm{N}$-terminus (wt, $\triangle \mathrm{DD}$ and S229A) were detected predominantly in the membrane fraction (Supplementary Figures $\mathrm{S} 2 \mathrm{a}, \mathrm{b}$ and $\mathrm{d}$ ). Conversely, a mutant lacking the $\mathrm{N}$-terminal transmembrane segment $(\Delta \mathrm{TM})$ was found in the hydrophilic fraction, indicating that this part of the protein mediates membrane association (Supplementary Figures S2a, b and $\mathrm{d}$ ).

$\mathrm{N}$-terminally anchored proteins can be inserted into membranes in two orientations. In type-Il anchor proteins, the $\mathrm{N}$-terminus remains in the cytosol and the $\mathrm{C}$-terminus is translocated into the ER lumen, whereas in type-III anchor proteins the topology is reversed. ${ }^{24}$ In case of Unc5CL the charge distribution around the TM domain hints to a type-III topology ('positive-inside rule'; Supplementary Figure S2a). ${ }^{25}$ This was confirmed by proteinase $\mathrm{K}$ protection assays (Supplementary Figures S2a and c). These results confirm that Unc5CL is anchored with its $\mathrm{N}$-terminus in the cell membrane with the $\mathrm{C}$-terminus containing the DD exposed to the cytosol.

Tissue distribution and subcellular localization. Querying of the GNF1M mouse tissue atlas shows Unc5CL expression in the uterus, small intestine and thymus (Supplementary Figure S3). ${ }^{26}$ To confirm this on protein level, a mouse tissue panel was probed using antibodies against the DD of Unc5CL (Figure 2a). Consistent with the microarray data, Unc5CL protein was confined to the uterus, ovary and gastrointestinal tract, with prominent expression in the small intestine. Furthermore, the C-terminal cleavage fragment was readily detected in these tissues, indicating that the protein is efficiently and constitutively processed in vivo. The expression in the small intestine and colon could be further confined to the epithelial cells. Unc5CL protein and mRNA were enriched in epithelial cell preparations from consecutive small intestinal segments, and could also be detected in colonic epithelial cells, albeit to a lesser extent (Figures $2 b$ and $c$ ). From the many cell lines that were tested for Unc5CL expression, only human colorectal CaCo-2 cells showed a convincing signal on western blots (Figure 2d). In line with the results observed in vivo, the C-terminal cleavage fragment was the prominent form detected. Specificity of the signal was confirmed by knockdown using Unc5CL-specific shRNAs (Figure 2d). As in HEK293T cells, Unc5CL was specifically found in the membrane fraction of CaCo-2 cells (Figure 2e).

CaCo-2 cells form a polarized intestinal epithelium (including tight junctions and apical microvilli) when grown to post-confluence, and are a well-established model for intestinal physiology. ${ }^{27}$ We therefore decided to use these cells to determine the subcellular localization of Unc5CL. 
A

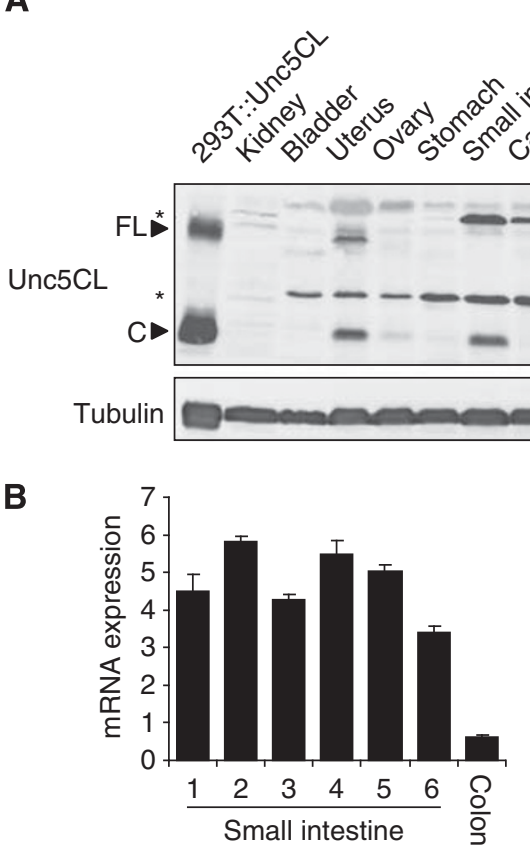

$\mathbf{F}$

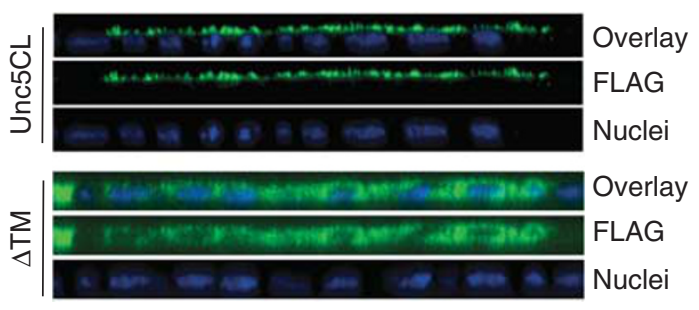

C

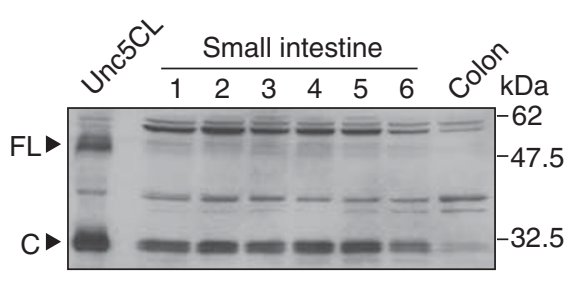

D

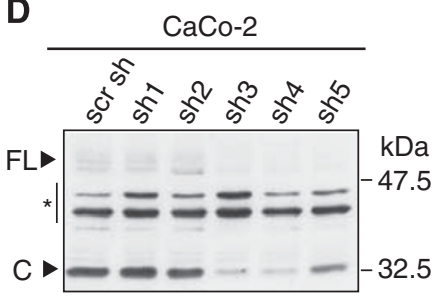

E

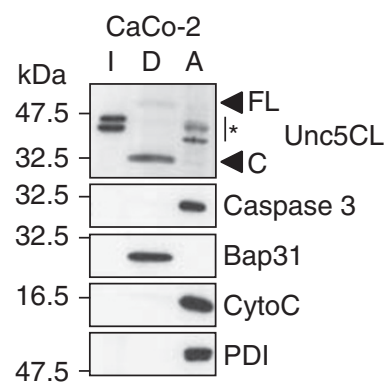

G

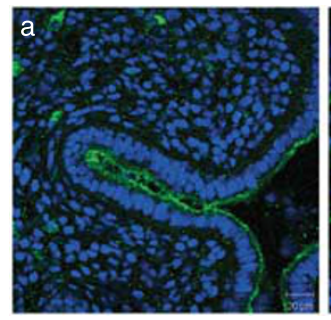

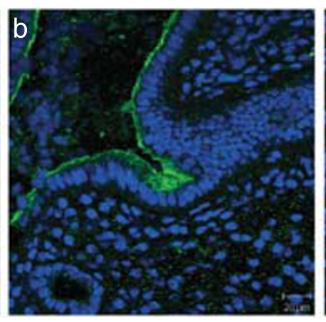

Figure 2 Tissue distribution and subcellular localization of Unc5CL. (A) Unc5CL-specific western blot of whole tissue lysates from the indicated tissues or overexpressed untagged Unc5CL as marker. (B) Relative Unc5CL mRNA expression in epithelial cell preparations from consecutive small intestinal (1-6) or colonic segments. Data represent the mean values \pm S.D. of technical triplicates. (C) Unc5CL-specific western blot of intestinal (1-6) and colonic epithelial samples shown in (B). (D) Unc5CL-specific western blot of lysates from CaCo-2 cells stably expressing mock (scr sh) or Unc5CL-specific shRNAs (sh1-sh5). (E) Proteins from CaCo-2 cells were subjected to TX-114 phase separation. Fractions were analyzed by western blot using the indicated antibodies. CytoC, $14 \mathrm{kDa}$ Cytochrome C, I, detergent-insoluble proteins, D, detergent phase, amphiphilic integral membrane proteins, A, aqueous phase, hydrophilic proteins. $(\mathbf{F})$ z-stack reconstruction following confocal microscopy of overexpressed $\mathrm{C}$-terminally FLAG-tagged Unc5CL (Unc5CL) or Unc5CL lacking the transmembrane domain $(\Delta T M)$ in $\mathrm{CaCo}-2$ cells using FLAG-specific antibodies. (G) (a-c) Immunofluorescent staining of Unc5CL on cryosections from OCT embedded uterus using Unc5CL-specific antibodies. Blue: nuclear DAPI staining. (a, b) Green: Unc5CL, (c) isotype control (FLAG). (A, D and E) Asterisks mark unspecific bands

Interestingly, ectopic Unc5CL was detected predominantly in microvilli-like structures on the apical face, whereas a mutant lacking the transmembrane domain showed cytosolic distribution (Figure 2f; Supplementary Figure S4a). In line with this observation we found strong enrichment of Unc5CL in microvilli-derived murine intestinal brush border membrane vesicles (Supplementary Figures $\mathrm{S} 4 \mathrm{~b}$ and $\mathrm{c}$ ). Immunohistochemistry using Unc5CL-specific antibodies suggests a similar apical epithelial localization in the uterine tissues (Figure 2g; Supplementary Figure S5).

Unc5CL is an activator of NF- $\kappa$ B and JNK. Many DD-containing proteins are involved in signal transduction events leading to activation of NF- $\kappa \mathrm{B}$ and JNK. ${ }^{14}$ As Unc5CL was previously implicated in the regulation of $\mathrm{NF}-\kappa \mathrm{B}$, it was pertinent to re-evaluate these findings. ${ }^{17}$ In contrast to previous observations, overexpression of the two human variants, Unc5CL $432 \mathrm{G}$ and $432 \mathrm{R}$, as well as murine Unc5CL led to a significant induction of NF- $\kappa \mathrm{B}$ in a luciferase assay (Figure 3a). Interestingly, the $432 \mathrm{G}$ variant was less potent than the $432 \mathrm{R}$ or the corresponding murine form, indicating that this single amino-acid variation in the DD has an influence on protein activity. MyD88, TNF-RI and TRAF6 were used as positive controls for NF- $\kappa$ B activation. By using the same assay we determined domain requirements for Unc5CL-dependent NF- $\kappa \mathrm{B}$ activation (Figure $3 b$ ). Firstly, an HFS to HFA mutant affecting the autoproteolytic cleavage site did not affect NF- $\kappa \mathrm{B}$ activation, indicating that the cleavage event per se is not required. Deletion of the transmembrane domain $(\Delta \mathrm{TM})$ or the ZU5 domain ( $\Delta \mathrm{ZU} 5$ ) showed an intermediate reduction in NF- $\kappa \mathrm{B}$ activity, which is more pronounced using the $\mathrm{C}$-terminal cleavage fragment only $(\mathrm{C})$, where both of these domains are missing. Also co-expression of the $\mathrm{N}$ - and $\mathrm{C}$-terminal cleavage fragments could not recapitulate the activity of the wild-type protein (Supplementary Figure S6). The strongest reduction in 

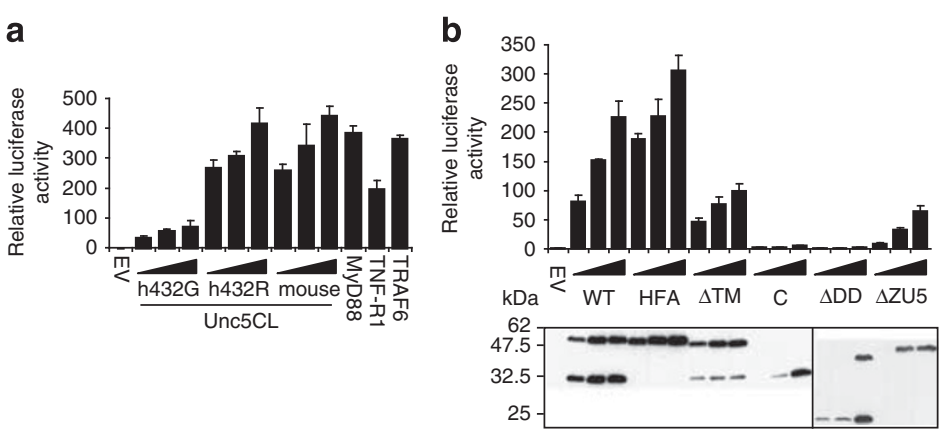

C

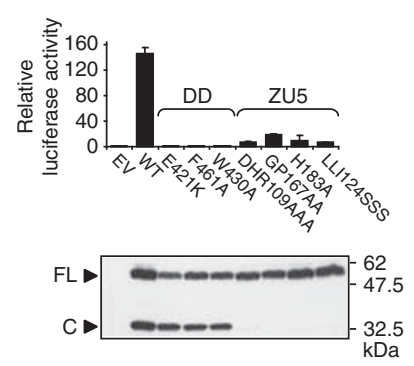

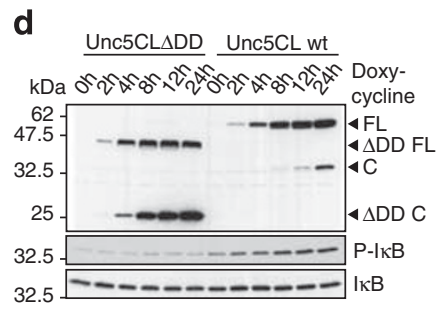

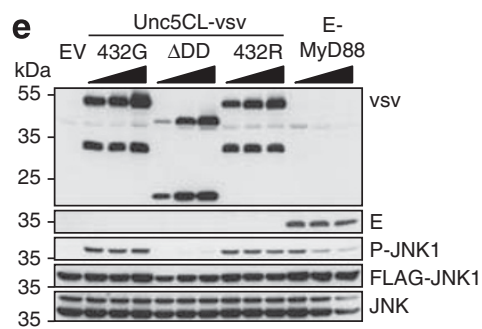

Figure 3 Unc5CL is an activator of NF- $\kappa$ B and JNK. (a-c) HEK293T cells were transfected with NF- $\kappa$ B luciferase reporter gene plasmids together with an empty vector $(\mathrm{EV})$ and increasing or single doses of the indicated expression constructs and were analyzed for NF- $\kappa \mathrm{B}$-dependent luciferase activity $24 \mathrm{~h}$ later. Data represent the mean values \pm S.D. of technical triplicates; results are representative of three independent experiments. (b and $\mathbf{c}$ ) The indicated expression constructs are based on Unc5CL genetic variant 432G. Proteins were analyzed by FLAG-specific western blot (d) HEK293 T-Rex cells stably containing doxycycline-inducible expression constructs for Unc5CL or Unc5CL $\triangle D D$ were treated with $200 \mathrm{ng} / \mathrm{ml}$ doxycycline for the indicated time. Expression of FLAG-tagged constructs and phosphorylation of $I_{\kappa} B$ were analyzed by western blot. (e) HEK293T cells were co-transfected with FLAG-JNK and the indicated constructs. Protein lysates were analyzed $24 \mathrm{~h}$ after transfection by western blot

NF- $\kappa$ B activity was observed with a mutant lacking the DD $(\triangle \mathrm{DD})$, indicating that the NF- $\kappa \mathrm{B}$-inducing capacity of Unc5CL requires this domain. To further characterize the importance of the DD and ZU5 domains, we generated point mutants in highly conserved regions that were predicted to interfere with the function of these domains. In line with the results described above, destabilization of the DD completely abrogated NF- $\kappa$ B activating capacity, whereas ZU5 mutants retained very low activity (Figure $3 c$ ). Of note, mutations affecting the ZU5 domain also impair the ability for autoprocessing, indicating that the cleavage requires a correct folding of this domain.

NF- $\kappa$ B activation, as evidenced by phosphorylation of $I_{\kappa} \mathrm{B} \alpha$, was also observed in HEK293 T-Rex cells, in which Unc5CL expression is induced by addition of doxycycline (Figure 3d).

Signaling cascades leading to NF- $\kappa$ B activation often also activate the kinase JNK. When we tested Unc5CL for this capacity in an overexpression assay, we indeed observed that both Unc5CL 432G and 432R, but not the mutant lacking the $\mathrm{DD}$, provoked the phosphorylation of co-expressed JNK1, confirming that Unc5CL is not only an activator of NF- $\kappa$ B but also of the kinase JNK (Figure 3e).

Transcriptional profiling identifies chemokines as Unc5CL targets. Several functions have been assigned to NF- $\kappa \mathrm{B}$, including induction of antiapoptotic and proinflammatory genes. ${ }^{28}$ The inducible HEK293 T-Rex cell line for Unc5CL described above was used in microarray experiments to determine genes that are transcriptionally regulated by Unc5CL overexpression. Interestingly, the most strongly induced genes, which were validated by real-time
PCR, were chemokines (CXCL1, CXCL2, CXCL3, IL-8 and CCL20) and several other NF- $\kappa$ B-dependent genes (TNFAIP3/A20, PLA2G4C and TNFRSF9; Figure 4a). ${ }^{29}$ The expression of another gene, MAP2K5, was unaffected by Unc5CL. Secretion of CXCL1, IL-8 and CCL20 upon Unc5CL overexpression was confirmed by ELISA (Figure $4 b$ ).

Unc5CL requires IRAK1, IRAK4 and TRAF6 but not MyD88 for NF- $\kappa$ B activation. Several DD containing proteins have been identified as essential components of signaling pathways leading to NF- $\kappa$ B activation. ${ }^{14}$ RIP1 is implicated in NF- $\kappa$ B activation in response to TNF $\alpha .{ }^{30}$ IRAK1, IRAK2 and IRAK4, together with the E3-ubiquitin ligase TRAF6, are involved in signaling downstream of most TLRs and IL-1R superfamily members. ${ }^{1-3}$ The adapter protein MyD88 links IRAK kinases to the respective receptors. To study the involvement of these proteins in Unc5CLinduced NF- $\kappa$ B activation, an siRNA approach was used. RIP1, IRAK1, IRAK4, MyD88 and TRAF6 were knocked down by transfection of gene-specific siRNAs, and the ability of Unc5CL to transactivate an NF- $\kappa$ B-specific luciferase reporter gene was assessed (Figures $5 a$ and b). Although knockdown of RIP1 affected neither Unc5CL- nor TLR2induced NF- $\kappa$ B, knockdown of IRAK1, IRAK4 and TRAF6 strongly impaired these signaling pathways. Moreover, knockdown of MyD88 only affected TLR2- but not Unc5CLinduced NF- $\kappa$ B activation, indicating that Unc5CL is involved in a novel IRAK-activating signaling cascade that uses the same signaling molecules as the TLR/IL-1R family. The same dependencies were observed for Unc5CLmediated IL-8 and CXCL1 secretion (Figures $5 c$ and d). 
a
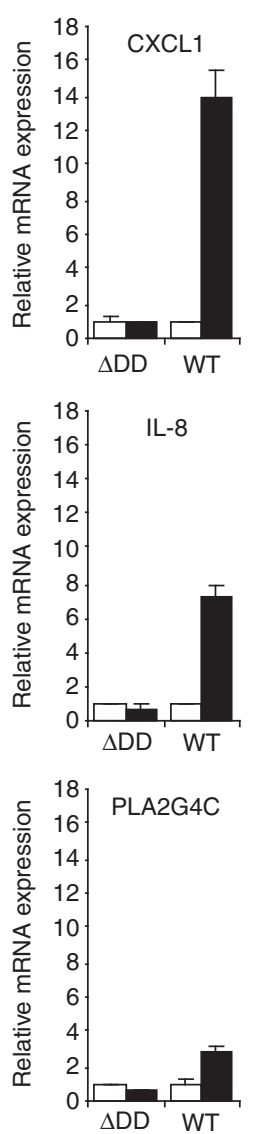

n.t. $\square$ Doxycyline
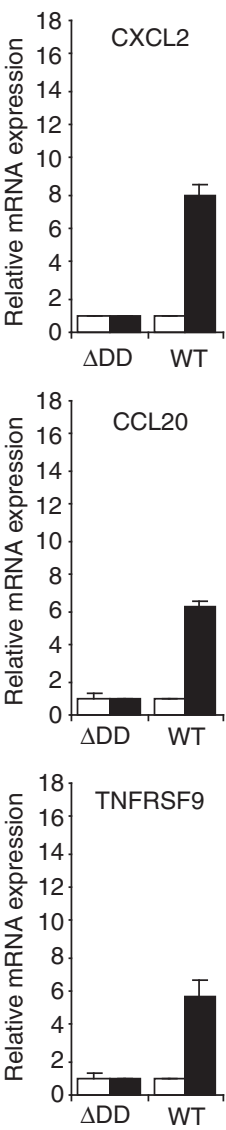
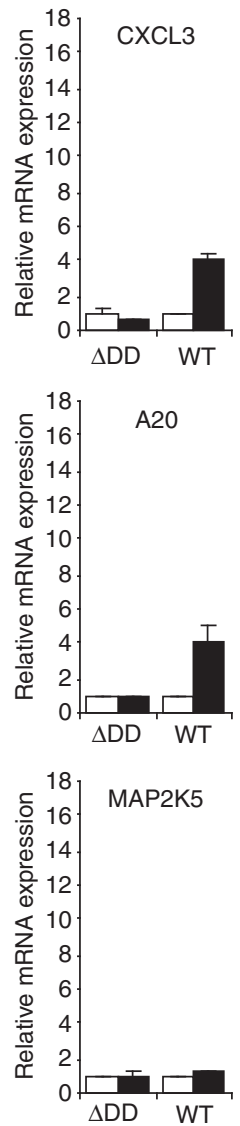

b
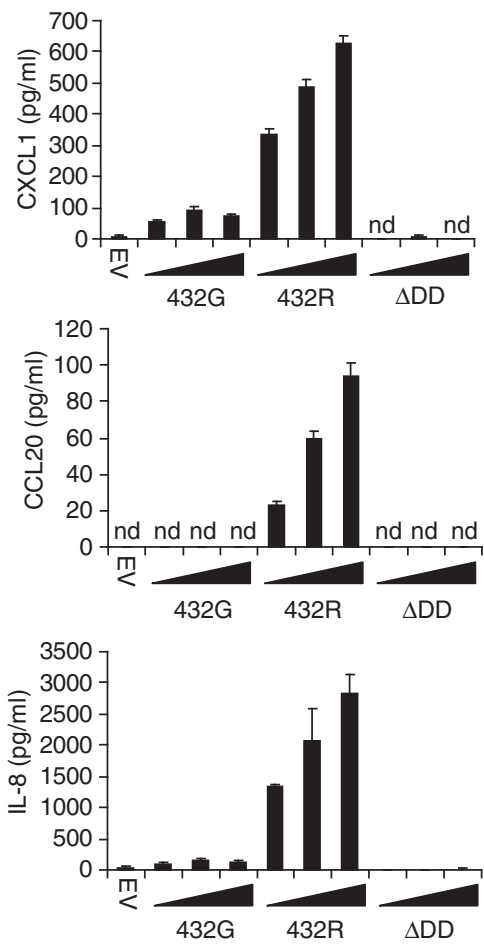

Figure 4 Unc5CL induces the expression and secretion of chemokines. (a) HEK293 T-Rex cells containing C-terminally FLAG-tagged Unc5CL (WT) or Unc5CLADD $(\triangle D D)$ were treated or not (n.t.) with $200 \mathrm{ng} / \mathrm{ml}$ doxycycline for $24 \mathrm{~h}$. Cells were harvested and RNA was prepared. Changes in the relative expression of the indicated Unc5CL target genes were determined by real-time PCR. (b) HEK293T cells were transfected with increasing doses of the indicated expression constructs. Supernatants were analyzed $24 \mathrm{~h}$ later by ELISA for secretion of CXCL1, IL-8 and CCL20. (a and $\mathbf{b}$ ) Data represent the mean values \pm S.D. of technical triplicates; results are representative of three independent experiments

Interactions between MyD88 and IRAK kinases are mediated in a DD-dependent manner. ${ }^{8,9}$ To test whether Unc5CL can also interact with IRAKs, co-immunoprecipitation experiments have been performed (Figure 5e). Wild-type or kinase-dead IRAK4 (IRAK4 kd) were co-expressed with Unc5CL 432G, Unc5CLADD or Unc5CL 432R. After immunoprecipitation of Unc5CL proteins, co-immunoprecipitation of overexpressed IRAK4 or endogenous IRAK1 was assessed. As expected, wild-type but not Unc5CL $\Delta D D$ interacted with both IRAK4 and IRAK4 $\mathrm{kd}$, as well as with endogenous IRAK1. Interestingly, Unc5CL variants $432 \mathrm{G}$ and 432R showed different affinities for IRAKs. Corresponding to the higher activity of Unc5CL $432 \mathrm{R}$ in NF- $\kappa \mathrm{B}$ luciferase reporter assays, this variant showed higher capacity to co-immunoprecipitate IRAK1 and IRAK4. Different degrees of activity of Unc5CL $432 \mathrm{G}$ and $432 \mathrm{R}$ may therefore be attributed to different affinities of the respective DD for IRAKs.

\section{Ligand-induced activation of Unc5CL signaling using a} chimeric receptor. As the activator of Unc5CL remains elusive, we created a fusion protein based on the DDcontaining TNF receptor family member EDAR to gain insight into the mechanism of Unc5CL activation (Supplementary Figure S7). EDAR is particularly well suited for this purpose, as the endogenous protein is confined to the ectoderm during development, and not found on HEK293T cells. ${ }^{31,32}$ The DD of EDAR was exchanged for the DD of Unc5CL 432R, or inactive point mutants $\mathrm{E} 421 \mathrm{~K}$ and $\mathrm{F} 461 \mathrm{~A}$. In transient overexpression, the chimeric receptor containing the DD of Unc5CL 432R showed similar capacity as wild-type EDAR to activate NF- $\kappa \mathrm{B}$ (Figure $6 \mathrm{a}$ ). In contrast, chimeras containing the inactivating point mutations were not able to activate $\mathrm{NF}-\kappa \mathrm{B}$, indicating that the NF- $\kappa \mathrm{B}$-activating ability of this chimeric receptor resides in the DD (Figure 6a). HEK293T cells stably expressing the chimeric receptor showed basal activation of $\mathrm{NF}-\kappa \mathrm{B}$, which was enhanced by treatment with Fc-EDA (a hexameric form of the EDAR ligand that causes receptor clustering). This demonstrated proof-of-principle that signaling via the Unc5CL DD can be induced (Figure 6b). Basal activation was also reflected by constitutive phosphorylation and degradation of $\mid \kappa \mathrm{B} \alpha$. (Figure $6 \mathrm{c}$ ). Interestingly, we also observed reduced levels of IRAK1 protein in cells expressing the Unc5CL chimeric receptor than in the mock-infected cells (Figure 6c). Furthermore, 
b
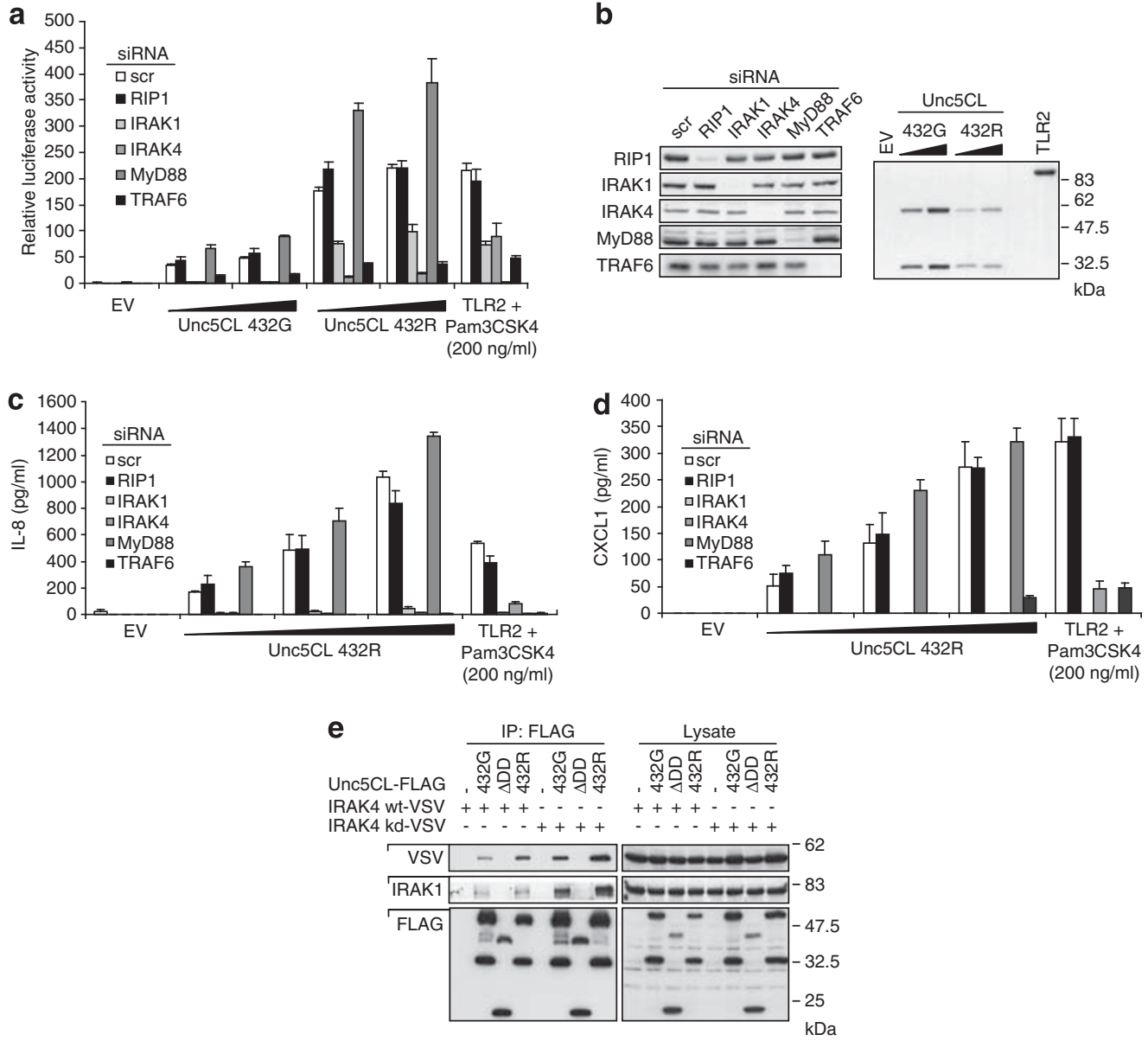

Figure 5 Unc5CL-mediated NF- $\kappa$ B activation is IRAK-dependent but MyD88-independent. (a) HEK293T cells were transfected with the indicated siRNAs. Forty eight hours later, cells were transfected with NF- $\kappa \mathrm{B}$ luciferase reporter gene plasmids together with an empty vector (EV) and the indicated expression constructs and were analyzed for NF- $\kappa$ B-dependent luciferase activity $24 \mathrm{~h}$ later. TLR2-transfected cells were additionally treated with $200 \mathrm{ng} / \mathrm{ml} \mathrm{Pam} 3 \mathrm{CSK} 4$. (b) Selected protein samples from experiments shown in (a) were probed by western blot using the indicated antibodies. (c and d) HEK293T cells were transfected with the indicated siRNAs. $48 \mathrm{~h}$ later, cells were transfected with the indicated expression constructs and supernatants were analyzed for IL-8 and CXCL1 secretion by ELISA. TLR2-transfected cells were additionally treated with $200 \mathrm{ng} / \mathrm{ml}$ Pam3CSK4. (a, c and d) Data represent the mean values \pm S.D. of technical triplicates; results are representative of three independent experiments. (e) HEK293T cells were transfected with the indicated expression constructs. Immunoprecipitates and extracts were analyzed by western blot using the indicated antibodies

treatment of these cells with Fc-EDA induced the appearance of higher molecular weight forms of IRAK1 (Figure 6c). These changes in IRAK1 most likely correlate with its activation. ${ }^{33}$ To more homogeneously activate the chimeric receptor, we identified a single-cell clone that showed low basal NF- $\kappa \mathrm{B}$ activation, but which could be efficiently induced by the ligand Fc-EDA. In a time course experiment, Fc-EDA induced rapid phosphorylation of $\mathrm{I}_{\kappa} \mathrm{B} \alpha$ followed by its degradation (Figure 6d). In line with the observation that Unc5CL is an activator of JNK, we also observed efficient phosphorylation of this kinase. As observed in the pool of chimeric-receptor expressing cells, higher molecular weight forms of IRAK1 appeared throughout the stimulation. To study activation-induced recruitment of signaling molecules to the chimeric receptor we combined Fc-EDA stimulation with subsequent immunoprecipitation of the ligand (Figure 6e). As expected, Fc-EDA efficiently co-precipitated its receptor EDARUnc5CL. Moreover, modified forms of IRAK1 and TRAF6 were recruited to the complex in a time-dependent manner. Analysis of the whole cell lysate again confirmed inducible phosphorylation and degradation of $\mathrm{I} \kappa \mathrm{B} \alpha$, phosphorylation of JNK and modification of IRAK1. Thus, ligand-induced oligomerization of the Unc5CL DD in the context of a receptor is sufficient to trigger signaling events that strongly resemble the MyD88-dependent branch of the TLR/IL1R family.

\section{Discussion}

In this study we found that Unc5CL is a novel inducer of a proinflammatory signaling cascade leading to activation of NF- $\kappa$ B and JNK. Dissection of the pathway identified the kinases IRAK1 and IRAK4, as well as the E3-ubiquitin ligase TRAF6 as essential downstream components. Most interestingly, MyD88, which is required for IRAK/TRAF6-dependent signaling downstream of IL-1- and Toll-like receptors, was dispensable for activity of Unc5CL. This finding indicates that 
a

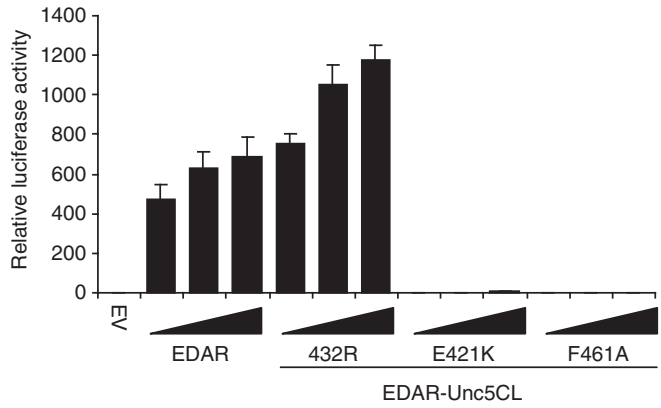

EDAR

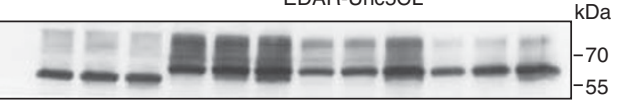

b

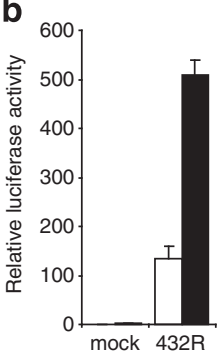

$\square$ n.t.

FC-EDA $(1 \mu \mathrm{g} / \mathrm{ml})$ c

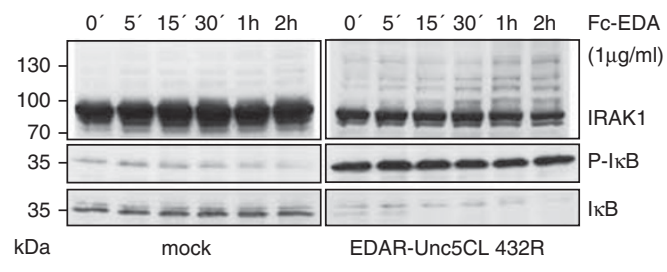

EDAR-Unc5CL 432R d

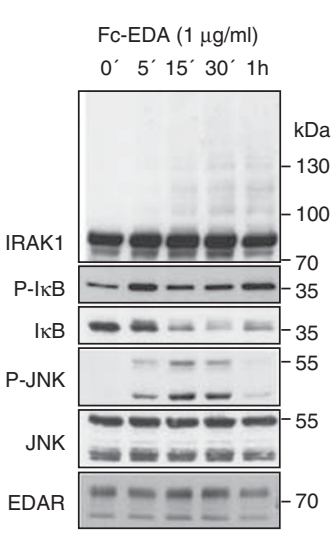

e
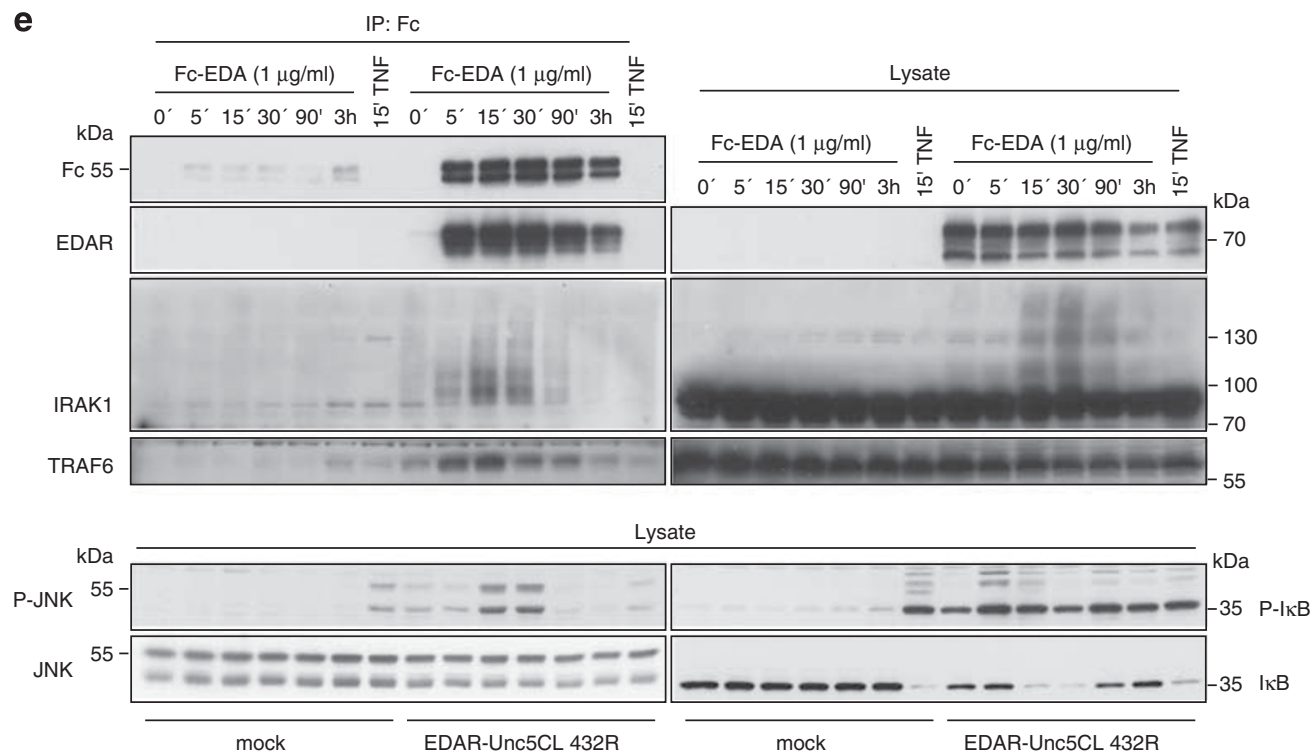

Figure 6 Ligand-induced activation of Unc5CL signaling. (a) HEK293T cells were transfected with NF- $\kappa$ B luciferase reporter gene plasmids together with an empty vector $(\mathrm{EV})$ or increasing or single doses of the indicated expression constructs and were analyzed for NF- $\kappa \mathrm{B}$-dependent luciferase activity $24 \mathrm{~h}$ later. $432 \mathrm{R}$ : EDAR-Unc5CL containing the Unc5CL DD variant 432R; E421K, F461A: EDAR-Unc5CL containing the Unc5CL DD with the indicated point mutations. The indicated expression constructs are based on Unc5CL genetic variant 432R. (b) Mock-infected or HEK293T cells ectopically expressing EDAR-Unc5CL were transfected with NF- $\kappa$ B luciferase reporter gene plasmids, were stimulated with $1 \mu \mathrm{g} / \mathrm{ml} \mathrm{Fc-EDA}$ for $24 \mathrm{~h}$ and were analyzed for NF- $\kappa$ B-dependent luciferase activity. (a and $\mathbf{b})$ Data represent the mean values \pm S.D. of technical triplicates; results are representative of three independent experiments. (c) Mock-transduced HEK293T cells or HEK293T cells stably expressing chimeric EDARUnc5CL receptor were stimulated for the indicated time with $1 \mu \mathrm{g} / \mathrm{ml} \mathrm{Fc-EDA}$. Protein lysates were analyzed by western blot using the indicated antibodies. (d) Clonal HEK293T cells stably expressing chimeric EDAR-Unc5CL receptor were stimulated for the indicated time with $1 \mu \mathrm{g} / \mathrm{ml} \mathrm{Fc-EDA}$. Protein lysates were analyzed by western blot using the indicated antibodies. (e) Mock-transduced HEK293T cells or clonal HEK293T cells stably expressing chimeric EDAR-Unc5CL receptor were stimulated for the indicated time with $1 \mu \mathrm{g} / \mathrm{ml} \mathrm{Fc-EDA} \mathrm{or} \mathrm{Fc-TNF.} \mathrm{Fc-EDA} \mathrm{and} \mathrm{associated} \mathrm{proteins} \mathrm{were} \mathrm{precipitated} \mathrm{from} \mathrm{protein} \mathrm{lysates} \mathrm{using} \mathrm{Protein} \mathrm{G} \mathrm{beads.} \mathrm{Precipitated} \mathrm{proteins} \mathrm{(IP} \mathrm{:} \mathrm{Fc)} \mathrm{or}$ cell lysates (Lysate) were analyzed by western blot using the indicated antibodies

Unc5CL provides a MyD88-independent second, parallel branch of the evolutionary conserved IRAK signaling cascade. While MyD88 is recruited to transmembrane receptors by virtue of its TIR domain, Unc5CL is already a membraneanchored protein. Both proteins contain a DD that is required for interaction with members of the IRAK family.

An intriguing feature of Unc5CL is its highly specific tissue distribution in mucosal epithelia, most abundantly in the uterus and intestine. This site provides an interface between the inside and outside of the body where epithelia have an essential barrier function against invading pathogens. ${ }^{34}$ Interestingly, the protein is sorted to the apical face of these cells. In light of the pro-inflammatory signal that is triggered upon Unc5CL activation, and lack of an extracellular domain, it is valid to speculate that, similar to MyD88, Unc5CL is used as a membrane-bound adapter protein for a hitherto unknown receptor that is activated by a luminal factor. However, it cannot be excluded that Unc5CL is activated by an intracellular membrane-proximal signal.

Our experiments using a chimeric EDAR-Unc5CL receptor revealed that oligomerization of the Unc5CL DD is important for signal initiation, presumably by providing an assembly platform for IRAKs. We therefore postulate that oligomerization, which is required for MyD88-dependent signaling, is also a prerequisite for wild-type Unc5CL activity, and that this is stimulated by the putative upstream factor.

Transcriptional profiling identified mainly pro-inflammatory chemokines such as IL-8, CXCL1 and CCL20 as downstream targets of Unc5CL. These factors are well known to orchestrate the initial phase of an immune response by 
recruitment of immune cells including neutrophils, macrophages, dendritic cells and $\mathrm{T}$ cells to sites of potential danger. ${ }^{35}$ It is therefore possible that Unc5CL is involved in responses to epithelial danger.

Unc5CL is constitutively autoproteolytically processed at an HFS site that is also found in PIDD and Nup98. ${ }^{21,22}$ While cleavage of the Nup98 precursor into mature nucleoporins Nup98 and Nup96 is required for its correct biogenesis and sorting to the nucleoplasmic side of the nuclear pore complex, inducible processing of PIDD is required for DNA damageinduced responses. ${ }^{21,36,37}$ Cleavage of Unc5CL appears constitutive and is not required for signaling, as evidenced by using a non-cleavable version (HFA). This hints to a role of Unc5CL autoprocessing in its biogenesis, localization or availability rather than activation, which should be addressed in future experiments.

Inflammatory bowel diseases (IBDs), including Crohn's disease and ulcerative colitis, are chronic inflammatory disorders predominantly affecting the small and large intestine They are thought to arise from a complex interplay of environmental factors in a genetically predisposed host. ${ }^{38}$ Though many genetic linkage studies have revealed a number of genetic risk loci, identified genes can only be attributed to ca $10-20 \%$ of human cases. Unc5CL was previously identified as marker for IBD, together with several other genes that are transcriptionally upregulated in the diseased tissues (United States Patent no. 20100004213). Considering, in addition, the pro-inflammatory activity and the strikingly specific expression in mucosal epithelia, we propose Unc5CL as a putative candidate molecule causally involved in mucosal diseases such as IBD. This warrants investigation of Unc5CL in future genetic association studies.

\begin{abstract}
Materials and Methods
Mice, cell culture and reagents. Six- to twelve-week-old mice were housed at the animal facility of the University of Lausanne. All animal procedures were conducted in compliance with Swiss federal legislation for animal experimentation. The human embryonic kidney HEK293T- and HEK293T-Rex cell lines (Invitrogen, Basel, Switzerland), were grown in Dulbecco's modified Eagle's medium (DMEM, Invitrogen) supplemented with $10 \%$ heat-inactivated fetal calf serum (FCS). The human colorectal adenocarcinoma cell line $\mathrm{CaCo}-2$ was maintained in DMEM supplemented with $15 \%$ FCS and 1\% MEM non-essential amino acids (Invitrogen). All cells were maintained in the presence of $100 \mathrm{U} / \mathrm{ml}$ penicillin and $100 \mu \mathrm{g} / \mathrm{ml}$ streptomycin (Invitrogen). Doxycyline, hydroxylamine and FLAG-peptide were obtained from Sigma (Buchs, Switzerland), Pam3CSK4 was from Invivogen (Nunningen, Switzerland). Fc-EDA and Fc-TNF were reported previously. ${ }^{32,39}$
\end{abstract}

Antibodies. Monoclonal mouse anti-FLAG (M2) and anti-VSV (P5D4), as well as rabbit polyclonal anti-FLAG and anti-VSV were from Sigma; anti-Unc5CL (AT116) and anti-cytochrome $\mathrm{C}(7 \mathrm{H} 6.2 \mathrm{C} 12)$ were from Apotech (Epalinges, Switzerland); anti-Bap31 (CC-1) from Alexis (Lausen, Switzerland). Anti-phosphoI $\kappa B(\# 9241)$ and anti-JNK (9252) from Cell Signaling (Allschwil, Switzerland); antiphospho-JNK (44-682G) from Biosource (Basel, Switzerland); anti-I $\kappa$ B (sc-371), anti-MyD88 (sc-74532) and anti-IRAK1 (sc-7883) from Santa-Cruz (Nunningen, Switzerland); anti-RIP1 ${ }^{38}$ and anti-caspase-3 (46) from Transduction Laboratories (Allschwil, Switzerland); anti-IRAK4 from ProSci (Lausen, Switzerland) (3125); anti-TRAF6 from MBL (Nunningen, Switzerland) (597).

Expression plasmids and siRNA. Human Unc5CL $432 R$ was amplified from a cDNA clone (GenBank: JF681947) by PCR and cloned in derivatives of pCR3 (Invitrogen), in frame with C-terminal FLAG and VSV tags. Unc5CL variant $432 G$ was generated by site-directed mutagenesis with two sequential rounds of PCR (double PCR). Unc5CL point and deletion mutants were generated by PCR or double PCR. pCR3 plasmids expressing N-terminally VSV-tagged human IRAK4 or IRAK4 kd and pCAGGS-E-MyD88 were reported previously. ${ }^{40}$ Retroviral pMSCV plasmids, expressing Unc5CL and mutants, were generated by subcloning from pCR3, lentiviral pRDI_292 plasmids (a kind gift from R Iggo, University of St Andrews, Scotland) were generated by PCR. The packaging plasmids for pMSCV, pCG (encoding VSV G envelope glycoprotein) and pHit60 (encoding gag and pol retroviral genes) were kind gifts of CA Benedict (San Diego, CA, USA). Packaging plasmids for lentiviral gene transfer, pMD2.G and pCMV $\triangle$ R8.91, were generously provided by Dr. Didier Trono. pcDNA5/FRT/TO plasmids (Invitrogen) for establishment of inducible HEK293 T-Rex cells were generated by subcloning from pCR3. The EDAR-Unc5CL fusion (EDAR aa 1-343, Unc5CL aa 402-518) was generated by double PCR and cloned in $\mathrm{PCR} 3$ or pMSCV. Derivatives corresponding to point mutations $\mathrm{E} 421 \mathrm{~K}$ and $\mathrm{F} 461 \mathrm{~A}$ were generated by double PCR. Lentiviral pLKO.1 plasmids expressing Unc5CL-specific shRNAs were obtained from Sigma. siRNAs were obtained from Ambion (Rotkreuz, Switzerland).

Transfection, immunoprecipitation and western blot. Transfections were performed using the calcium-phosphate precipitation technique. Cells were usually lysed in Nonidet $P$ (NP)-40 lysis buffer $(0.1 \%$ NP-40, $50 \mathrm{mM}$ Tris pH 8.0, $150 \mathrm{mM} \mathrm{NaCl}, 5 \mathrm{mM}$ EDTA, $1 \mathrm{mM} \mathrm{NaVO}_{4}$, complete protease inhibitor cocktail; Roche, Basel, Switzerland) for $15 \mathrm{~min}, 4^{\circ} \mathrm{C}$. Murine tissue lysates were equally generated in RIPA buffer (10 mM Tris-HCl, pH 7.5, $150 \mathrm{mM} \mathrm{NaCl}, 1 \% \mathrm{NP}-40,1 \%$ sodium deoxycholate, $0.1 \%$ SDS, $1 \mathrm{mM}$ EDTA and protease inhibitor mix) using a rotor-statortype tissue homogeniser ART Miccra D-8 (Müllheim, Germany) (4 pulses of $10 \mathrm{~s}, 4^{\circ} \mathrm{C}$ ).

Lysates were cleared by centrifugation in a microcentrifuge (13000 r.p.m., $10 \mathrm{~min}, 4^{\circ} \mathrm{C}$ ) and resolved by SDS-PAGE. Proteins were transferred onto nitrocellulose membranes (Amersham, Glattbrugg, Switzerland) and probed using the indicated antibodies.

siRNAs at final concentrations of $10 \mathrm{nM}$ were also transfected into HEK293T cells using the calcium-phosphate precipitation technique.

For immunoprecipitation, $24 \mathrm{~h}$ after transfection cells were harvested and lysed as described above. Lysates were incubated for $1 \mathrm{~h}$ at $4^{\circ} \mathrm{C}$ with $20 \mu \mathrm{l}$ sepharose6B (Sigma) on a rotating wheel for a pre-clearing step. After centrifugation (5000 r.p.m., $1 \mathrm{~min}, 4^{\circ} \mathrm{C}$ ) $1 / 10$ supernatant (SN) was frozen (loaded as a cell extract control the following day) and $9 / 10 \mathrm{SN}$ was immunoprecipitated $\mathrm{O} / \mathrm{N}$ at $4^{\circ} \mathrm{C}$ on a rotating wheel, with $15 \mu$ of a 1:2 mixture of FLAG M2-agarose beads (Sigma) and sepharose6B beads or $15 \mu \mathrm{l}$ protein $\mathrm{G}$ beads. After extensive washing of the beads with lysis buffer the cell extracts and immunoprecipitates were loaded on a SDS-PAGE and the proteins were revealed by western blotting.

In vitro cleavage assays. HEK293T cells in $10 \mathrm{~cm}$ dishes were transfected with C-terminally FLAG-tagged expression vectors for Unc5CL that contain point mutations in the autoproteolytic HFS site (HFA, HFC). $24 \mathrm{~h}$ later cells were lysed and Unc5CL was immunoprecipitated as described above. FLAG-tagged proteins were washed and eluted by incubation for $10^{\prime}$ at RT with $120 \mu \mathrm{l} 3 \times$ FLAG peptide (Sigma, $100 \mu \mathrm{g} / \mathrm{ml}$ in lysis buffer). In all $20 \mu$ l of every eluate was kept for later analysis ( $0 \mathrm{~h}$ time point), the rest was divided in three parts. One part was left untreated, the other two were incubated with $200 \mathrm{mM}$ hydroxylamine $\left(\mathrm{NH}_{2} \mathrm{OH}\right)$ with or without $2 \%$ SDS. $20 \mu \mathrm{l}$ samples were taken at the indicated time points, mixed with SDS-sample buffer and analyzed by western blot.

Luciferase reporter assays. Cells in 24-well dishes were co-transfected in triplicate with $40 \mathrm{ng} \mathrm{NF}-\kappa \mathrm{B}$ firefly luciferase reporter gene constructs, in combination with $40 \mathrm{ng}$ phRLTK (encodes a constitutively expressed Renilla luciferase), the indicated constructs, and an empty vector to normalize for the total quantity of $240 \mathrm{ng} /$ well transfected DNA. $24 \mathrm{~h}$ after transfection, cells were either stimulated for the indicated periods or lysed in passive lysis buffer (Promega, Dübendorf, Switzerland), and dual luciferase activity was measured in a Packard Top-Count NXT (PerkinElmer, Schwerzenbach, Switzerland) using the Dual-Luciferase Reporter Assay System (Promega), according to the manufacturer's instructions.

Triton X-114 phase separation. Triton X-114 (TX114) phase separation experiments were performed as described in Bordier. ${ }^{23}$ Briefly, $5 \times 10^{6}$ HEK293T cells stably expressing the indicated mutants were resuspended in $500 \mu \mathrm{lPBS}$ and $100 \mu \mathrm{l} 6 \%$ pre-condensed TX114, mixed by pipetting/inversion and incubated for $15 \mathrm{~min}$ on ice. The samples were centrifuged for $1 \mathrm{~min}$ at 13000 r.p.m., the supernatants were transferred to new tubes, the pellets, which correspond to the insoluble fractions, were resuspended in $200 \mu$ l SDS-sample buffer by sonication. The supernatants were incubated for $5 \mathrm{~min}$ at $37^{\circ} \mathrm{C}$ to induce phase separation and 
centrifuged for $1 \mathrm{~min}$ at 13000 r.p.m. at room temperature. The upper aqueous phases were transferred to new tubes. To wash, the lower, detergent phase was mixed with $500 \mu \mathrm{l}$ PBS, the upper phase with $100 \mu \mathrm{l} 6 \%$ TX114 and incubated for $5 \mathrm{~min}$ on ice and for $5 \mathrm{~min}$ at $37^{\circ} \mathrm{C}$. Samples were centrifuged again and the initial phases were kept for further processing. Proteins were precipitated by adding $500 \mu \mathrm{l}$ methanol and $125 \mu \mathrm{l}$ chloroform to the aqueous phases and $450 \mu \mathrm{l}$ PBS $500 \mu \mathrm{l}$ methanol and $125 \mu \mathrm{l}$ chloroform to the detergent phases, followed by vortexing. Samples were centrifuged for 4 min at 13000 r.p.m., $750 \mu$ l of the upper phases was removed and $400 \mu \mathrm{l}$ methanol was added and mixed by pipetting. Samples were centrifuged again for $1 \mathrm{~min}$ at 13000 r.p.m., supernatants were removed and the pellets were dried under the chemical hood. Precipitated proteins from the aqueous phase were resuspended in $200 \mu \mathrm{l}$, those from the detergent phase in $50 \mu \mathrm{l}$ SDS-sample buffer. Proteins were solubilized by sonication and analyzed by western blot.

ELISA. Twenty four hours after transfection of HEK293T cells in 24-well plates, cell supernatants were analyzed for human CXCL1, CCL20 (R\&D Systems, Abingdon, UK) and IL-8 expression (Immunotools, Friesoythe, Germany) by enzymelinked immunosorbent assay (ELISA), according to the manufacturer's instructions.

Preparation of intestinal epithelial cells. The small intestine and colon were wholly dissected from euthanized C57BL/6 mice (6-12 weeks of age), cut in ca $3-\mathrm{cm}$ sections, freed from residual feces and mucus after longitudinal section and transferred in ice-cold Hanks' balanced salt solution (HBSS) without $\mathrm{Ca}^{2+}$ and $\mathrm{Mg}^{2+}$ (Invitrogen). After rinsing several times in HBSS at RT, residues were shaken gently in $15 \mathrm{ml}$ of HBSS containing $2 \mathrm{mM}$ EDTA (pH 8.0) for $30 \mathrm{~min}$ at $37^{\circ} \mathrm{C}$. The solid material was transferred to a new $50 \mathrm{ml}$ tube containing $20 \mathrm{ml}$ PBS and the supernatant was discarded. The remaining mucosa was vortexed vigorously and the supernatant containing complete crypts and some single cells were collected into a fresh $50 \mathrm{ml}$ tube. Single cells and crypts were centrifuged at $400 \mathrm{~g}$ for $5 \mathrm{~min}$ at $4^{\circ} \mathrm{C}$.

\section{Conflict of Interest}

The authors declare no conflict of interest.

Acknowledgements. We thank $C$ Thomas for critically reading the manuscript and A Tardivel, S Hertig, G Guarda and TK Vogt for their technical help. This work was supported by grants from the Swiss National Science Foundation, NCCR Molecular Oncology, the EU-FP6 framework program RTN-ApopTrain, the Institute for Arthritis Research and Fondation Louis-Jeantet.

\section{Author Contributions}

LXH and JT designed research; LXH, MR, DCR, FS, KS, MQ, OG and PS performed the experiments; $L X H, K S$ and $O G$ analyzed the data; $L X H$ and JT wrote the paper.

1. O'Neill LA. The interleukin-1 receptor/Toll-like receptor superfamily: 10 years of progress Immunol Rev 2008; 226: 10-18.

2. Kawai $T$, Akira $S$. The role of pattern-recognition receptors in innate immunity: update on Toll-like receptors. Nat Immunol 2010; 11: 373-384

3. Kawai T, Akira S. TLR signaling. Semin Immunol 2007; 19: 24-32.

4. Muzio M, Ni J, Feng P, Dixit VM. IRAK (Pelle) family member IRAK-2 and MyD88 as proximal mediators of IL-1 signaling. Science 1997; 278: 1612-1615.

5. Wesche H, Henzel WJ, Shillinglaw W, Li S, Cao Z. MyD88: an adapter that recruits IRAK to the IL-1 receptor complex. Immunity 1997; 7: 837-847.

6. Burns K, Martinon F, Esslinger C, Pahl H, Schneider P, Bodmer JL et al. MyD88, an adapter protein involved in interleukin-1 signaling. J Biol Chem 1998; 273 12203-12209.

7. Medzhitov R, Preston-Hurlburt P, Kopp E, Stadlen A, Chen C, Ghosh S et al. MyD88 is an adaptor protein in the hToll/L-1 receptor family signaling pathways. Mol Cell 1998; 2 : 253-258.

8. Motshwene PG, Moncrieffe MC, Grossmann JG, Kao C, Ayaluru M, Sandercock AM et al. An oligomeric signaling platform formed by the Toll-like receptor signal transducers MyD88 and IRAK-4. J Biol Chem 2009; 284: 25404-25411.

9. Lin SC, Lo YC, Wu H. Helical assembly in the MyD88-IRAK4-IRAK2 complex in TLR/LL-1R signalling. Nature 2010; 465: 885-890.
10. Cao Z, Xiong J, Takeuchi M, Kurama T, Goeddel DV. TRAF6 is a signal transducer for interleukin-1. Nature 1996; 383: 443-446

11. Dinarello CA. Immunological and inflammatory functions of the interleukin-1 family. Annu Rev Immunol 2009; 27: 519-550.

12. Chen K, Huang J, Gong W, Iribarren P, Dunlop NM, Wang JM. Toll-like receptors in inflammation, infection and cancer. Int Immunopharmacol 2007; 7: 1271-1285.

13. Picard C, von Bernuth $\mathrm{H}$, Ghandil P, Chrabieh M, Levy O, Arkwright PD et al. Clinical features and outcome of patients with IRAK-4 and MyD88 deficiency. Medicine (Baltimore) 2010; 89: 403-425.

14. Park HH, Lo YC, Lin SC, Wang L, Yang JK, Wu H. The death domain superfamily in intracellular signaling of apoptosis and inflammation. Annu Rev Immunol 2007; 25: $561-586$

15. Reed JC, Doctor KS, Godzik A. The domains of apoptosis: a genomics perspective. Sci STKE 2004; 2004: re9.

16. Wang R, Wei Z, Jin H, Wu H, Yu C, Wen W et al. Autoinhibition of UNC5b revealed by the cytoplasmic domain structure of the receptor. Mol Cell 2009; 33: 692-703.

17. Zhang J, Xu LG, Han KJ, Shu HB. Identification of a ZU5 and death domain-containing inhibitor of NF-kappaB. J Biol Chem 2004; 279: 17819-17825.

18. Cole C, Barber JD, Barton GJ. The Jpred 3 secondary structure prediction server. Nucleic Acids Res 2008; 36 (Web Server issue): W197-W201.

19. Larkin MA, Blackshields G, Brown NP, Chenna R, McGettigan PA, McWilliam H et al. Clustal W and Clustal X version 2.0. Bioinformatics 2007; 23: 2947-2948.

20. Krogh A, Larsson B, von Heijne G, Sonnhammer EL. Predicting transmembrane protein topology with a hidden Markov model: application to complete genomes. J Mol Biol 2001; 305: $567-580$.

21. Tinel A, Janssens S, Lippens S, Cuenin S, Logette E, Jaccard B et al. Autoproteolysis of PIDD marks the bifurcation between pro-death caspase-2 and pro-survival NF-kappaB pathway. EMBO J 2007; 26: 197-208.

22. Rosenblum JS, Blobel G. Autoproteolysis in nucleoporin biogenesis. Proc Natl Acad Sci USA 1999; 96: 11370-11375.

23. Bordier C. Phase separation of integral membrane proteins in Triton X-114 solution. J Biol Chem 1981; 256: 1604-1607.

24. Spiess M. Heads or tails-what determines the orientation of proteins in the membrane. FEBS Lett 1995; 369: 76-79.

25. Beltzer JP, Fiedler K, Fuhrer C, Geffen I, Handschin C, Wessels HP et al. Charged residues are major determinants of the transmembrane orientation of a signal-anchor sequence. J Biol Chem 1991; 266: 973-978.

26. Su Al, Wiltshire T, Batalov S, Lapp H, Ching KA, Block D et al. A gene atlas of the mouse and human protein-encoding transcriptomes. Proc Natl Acad Sci USA 2004; 101: 6062-6067.

27. Meunier V, Bourrie M, Berger Y, Fabre G. The human intestinal epithelial cell line Caco-2; pharmacological and pharmacokinetic applications. Cell Biol Toxicol 1995; 11 . 187-194.

28. Hayden MS, Ghosh S. Signaling to NF-kappaB. Genes Dev 2004; 18: 2195-2224.

29. Vallabhapurapu S, Karin M. Regulation and function of NF-kappaB transcription factors in the immune system. Annu Rev Immunol 2009; 27: 693-733.

30. Ting AT, Pimentel-Muinos FX, Seed B. RIP mediates tumor necrosis factor receptor 1 activation of NF-kappaB but not Fas/APO-1-initiated apoptosis. EMBO J 1996; 15: 6189-6196.

31. Laurikkala J, Pispa J, Jung HS, Nieminen P, Mikkola M, Wang X et al. Regulation of hair follicle development by the TNF signal ectodysplasin and its receptor Edar. Development 2002; 129: 2541-2553.

32. Bossen C, Ingold K, Tardivel A, Bodmer JL, Gaide O, Hertig S et al. Interactions of tumor necrosis factor (TNF) and TNF receptor family members in the mouse and human. J Biol Chem 2006; 281: 13964-13971.

33. Yamin TT, Miller DK. The interleukin-1 receptor-associated kinase is degraded by proteasomes following its phosphorylation. J Biol Chem 1997; 272: 21540-21547.

34. Gribar SC, Richardson WM, Sodhi CP, Hackam DJ. No longer an innocent bystander: epithelial toll-like receptor signaling in the development of mucosal inflammation. $\mathrm{Mol} \mathrm{Med}$ 2008; 14: 645-659.

35. Viola A, Luster AD. Chemokines and their receptors: drug targets in immunity and inflammation. Annu Rev Pharmacol Toxicol 2008; 48: 171-197.

36. Fontoura BM, Blobel G, Matunis MJ. A conserved biogenesis pathway for nucleoporins: proteolytic processing of a 186-kilodalton precursor generates Nup98 and the novel nucleoporin, Nup96. J Cell Biol 1999; 144: 1097-1112.

37. Janssens S, Tinel A, Lippens S, Tschopp J. PIDD mediates NF-kappaB activation in response to DNA damage. Cell 2005; 123: 1079-1092.

38. Kaser A, Zeissig S, Blumberg RS. Inflammatory bowel disease. Annu Rev Immunol 2010; 28: $573-621$

39. Gaide 0 , Schneider P. Permanent correction of an inherited ectodermal dysplasia with recombinant EDA. Nat Med 2003; 9: 614-618.

40. Burns K, Janssens S, Brissoni B, Olivos N, Beyaert R, Tschopp J. Inhibition of interleukin 1 receptor/Toll-like receptor signaling through the alternatively spliced, short form of MyD88 is due to its failure to recruit IRAK-4. J Exp Med 2003; 197: 263-268. 